\title{
LEVANTAMENTO DE DOENÇAS EM IPÊ-AMARELO (Tabebuia chrysotricha) EM CURITIBA, PR
}

\author{
Patricia. Wielewski ${ }^{1}$ \\ Celso Garcia Auer ${ }^{2}$ \\ Albino Grigoletti Junior ${ }^{3}$
}

\begin{abstract}
RESUMO
Uma das espécies mais utilizadas na arborização de Curitiba é o ipê-amarelo, Tabebuia chrysotricha (Mart, ex DC.) Standl. Em 1998, verificaram-se algumas anormalidades em árvores de ipê-amarelo, em vias públicas de Curitiba, como a floração irregular e a redução da frutificação. As seguintes hipóteses foram formuladas, para explicar estas anormalidades: mudanças climáticas, estresse, idade das árvores e a ocorrência de doenças. Neste estudou-se as principais doenças do ipê-amarelo, na Região Metropolitana de Curitiba. Análises fitopatologicas foram feitas em sementes, em mudas e em árvores, em área urbana. As sementes apresentaram fungos potencialmente patogênicos como Fusarium, Alternaria, Phomopsis e Phoma. As doenças constatadas em mudas e árvores de ruas foram a crosta-marrom causada por Apiosphaeria guaranitica, o oídio e a fumagina. A doença crosta-marrom revelou-se como a mais severa e prevalente em áreas urbanizadas.

Palavras chave : arborização urbana, diagnose, fungo, patologia de sementes
\end{abstract}

\section{SURVEY OF DISEASES ON IPÊ- AMARELO (Tabebuia chrysotricha) IN CURITIBA, PARANÁ STATE}

\begin{abstract}
One of the most used tree for urban forestry at Curitiba is ipê-amarelo, Tabebuia chrysotricha (Mart, ex DC.) Standl. In 1998, some anormalyties were noted on ipê-amarelo trees, on Curitiba streets, such as irregular flowering and fruiting. In order to explain this fact, some hypotheses were formulated: climate change, tree age and occurrence of diseases. This study was developed to know the diseases on this species, at Metropolitan Region of Curitiba. Seed pathology and diagnosis of diseases were performed on seeds, seedlings and urban trees. Pathological analysis on seeds revealed potential pathogenic fungi as Fusarium, Alternaria, Phomopsis and Phoma. The following diseases were found on seedlings and trees: corky leaf spot of ipê-amarelo caused by Apiosphaeria guaranitica, powdery mildew and sooty mold. The most frequent and severe disease on trees was corky leaf spot, in urban areas.

Key-words: diagnosis, fungi, seed pathlogy, urban tree
\end{abstract}

\section{INTRODUÇÃO}

As árvores contribuem para tornar o ambiente urbano mais agradável, melhorando as condições de vida nas cidades. Dentre as espécies mais plantadas na arborização urbana de Curitiba, está o ipê-amarelo, Tabebuia chrysotricha (Mart. ex DC.) Standl. Esta espécie é considerada importante para plantio em área urbana, principalmente pelo seu porte baixo e sua aceitação pela população. Trata-se de uma árvore com belíssima floração amarela, que antecedendo a primavera. Uma outra espécie de ipê-amarelo, também utilizada neste município, é a Tabebuia alba (Chamisso) Sandwith.

Em 1998, nas vias públicas de Curitiba, foram observadas as seguintes anormalidades nas árvores de $T$. chrysotricha: a irregularidade na quantidade e freqüência do florescimento e a redução de frutificação. Algumas hipóteses foram inferidas acerca das anormalidades citadas, tais como a ocorrência de doenças, a alteração nas condições climáticas daquele

grilopg@ig.com.br. Eng. Florestal., M.Sc,

2 auer@cnpf.embrapa.br. Eng. Florestal, D. Sc., pesquisador da Embrapa Florestas

albino@cnpf.embrapa.br. Eng. Agrônomo, D. Sc., pesquisador da Embrapa Florestas

Recebido para publicação: 20/02/2002

Aceito para publicação: 20/12/2002 
ano, o estresse causado pela pressão urbana (insuficiente arejamento para as raízes, déficit hídrico ocasional, agentes poluentes e injúrias mecânicas, temperaturas extremas, entre outros) e a senescência precoce das árvores, aspectos urbanos comentados por Marchetti et al. (1997) e Ragazzi (1997).

Outras agressões sofridas pelas árvores localizadas em vias públicas decorrem da ação de pragas e doenças. Um estudo feito por Milano (1984) revelou que T. chrysotricha era a quinta espécie mais plantada em Curitiba e que $68 \%$ das árvores analisadas necessitavam de controle de doenças e pragas; portanto uma espécie altamente suscetível à pragas. Em $T$. chrysotricha ocorrem algumas doenças e a mais comum é a crosta-marrom (Auer, 1996; Ferrreira, 1989).

No caso da poluição, os ipês-amarelos são considerados tolerantes aos poluentes urbanos (Carvalho, 1994; Biondi, 1995).

Assim, o objetivo deste estudo foi conhecer as principais doenças e problemas em ipê-amarelo ( $T$. chrysotricha), em áreas urbanas da Região Metropolitana de Curitiba.

\section{MATERIAIS E MÉTODOS}

As áreas de estudo localizaram-se, principalmente, na cidade de Curitiba. A cidade está localizada a $25^{\circ} 25^{\prime} 48^{\prime \prime} \mathrm{S}$ e $49^{\circ} 16^{\prime}$ 15" W, (Instituto de Pesquisa e Planejamento Urbano de Curitiba, 1991). De acordo com a classificação de Koeppen, o clima é do tipo $\mathrm{Cfb}$, sempre úmido, pluvial quente-temperado. A temperatura média anual é de $16,5^{\circ} \mathrm{C}$, sendo $24,4{ }^{\circ} \mathrm{C}$ nos meses mais quentes e $12,7{ }^{\circ} \mathrm{C}$ nos meses mais frios, com mais de 5 geadas por ano e precipitação anual de 1.450,8 $\mathrm{mm}$ (Maack, 1968). Parte dos estudos foram feitos no viveiro do Horto Municipal da Barreirinha, pertencente à Prefeitura Municipal de Curitiba, onde são produzidas as mudas de ipê-amarelo para arborização. A outra parte dos estudos foi feita em árvores da Região Metropolitana de Curitiba, em diversas fases de desenvolvimento, nos seguintes locais: rua Menezes Dória; avenidas Sete de Setembro, Professor Lothário Meissner e Anita Garibaldi; Parque São Lourenço (município de Curitiba) e arboreto da Embrapa Florestas (município de Colombo).
Neste levantamento de doenças, foram desenvolvidos três estudos. No primeiro ensaio, fez-se uma avaliação da população fúngica associada às sementes, por meio do método "blotter test" (Neergaard, 1977). Foram empregadas 400 sementes de ipêamarelo não esterilizadas, coletadas de árvores de rua. Os gerbox foram lavados com água corrente e com hipoclorito de sódio $1 \%$. Logo após a secagem, colocaram-se 3 folhas de papel filtro autoclavadas e umedecidas com água esterilizada, em cada um. Vinte sementes foram colocadas em cada gerbox. As observações e as contagens dos microrganismos foram realizadas no $7^{\circ}$ dia e a segunda contagem no $10^{\circ}$ dia, com auxílio de microscópios estereoscópio e ótico.

O segundo estudo foi um acompanhamento da ocorrência de doenças em mudas, no viveiro, por dois anos. Material doente foi examinado no Laboratório de Fitopatologia, da Embrapa Florestas, fazendose o exame direto de estruturas fúngicas no material doente, exame de material mantido em câmara úmida por uma semana e exame de cultura produzidas em meio BDA, a partir de isolamento indireto de fragmentos de tecidos lesionados para o meio de cultura.

O terceiro estudo foi uma avaliação da ocorrência de doenças em árvores. Foram examinadas 60 árvores localizadas em vias públicas e 20 localizadas em parque e $20 \mathrm{em}$ arboreto, com alturas variando entre 2 e 4 metros e idade acima de 2 anos. Material doente foi examinado de acordo com os métodos apresentados no segundo ensaio, para identificação do agente causal. Os fungos encontrados foram identificados com base em descrições micológicas de Barnett e Hunter (1972), Sutton (1980), Luz (1987) e Ferreira (1989).

\section{RESULTADOS E DISCUSSÃO}

No estudo com sementes, cerca da metade das mesmas $(47,75 \%)$ estavam contaminadas com fungos potencialmente patogênicos (tab. 1). O fungo Fusarium foi o mais freqüente dentre os patogênicos, incluindo Alternaria, Phomopsis e Phoma, os quais normalmente causam desde apodrecimento de sementes até tombamento de plântulas e de mudas de espécies florestais 
(Santos et al., 2000). Somente $24 \%$ das sementes apresentavam-se sadias e pouco mais de $8 \%$ germinaram. Em sementes de ipêamarelo, T. serratifolia, Carvalho e Muchovej (1991) encontraram vários fungos destacandose Alternaria tenuissima, Diplodia sp., Fusarium equisetii, $F$. moniliforme, $F$. pallidoroseum e Sphaeropsis sapinea como possivelmente patogênicos. A baixa germinação das sementes analisadas pode ser decorrente do ataque dos fungos nas sementes (Santos et al., 2000) ou da baixa qualidade das mesmas. Estes resultados indicam a necessidade de se melhorar o procedimento na coleta de sementes ou de se efetuar o tratamento das sementes com fungicidas, antes da semeadura.

Tabela 1: Fungos em sementes de Tabebuia chrysotricha

Table 1: Fungi on seeds of Tabebuia chrysotricha

\begin{tabular}{lc}
\hline GÊNEROS DE FUNGOS & $\begin{array}{c}\text { FREQÜÊNCIA (\%)* } \\
\text { Fungi genera }\end{array}$ \\
\hline Fusarium & 36,50 \\
Trichoderma & 14,75 \\
Alternaria & 3,00 \\
Phomopsis & 0,75 \\
Torula & 0,25 \\
Epicoccum & 1,50 \\
Pestalotia & 0,25 \\
Chaetomium & 0,25 \\
Phoma & 0,50 \\
Trichoderma + Torula & 0,25 \\
Fusarium + Trichoderma & 0,75 \\
Fusarium + NI & 0,25 \\
Fusarium + Alternaria & 1,25 \\
Trichoderma + Epicoccum & 0,25 \\
Alternaria + NI & 0,25 \\
Fusarium + Chaetomium & 0,50 \\
Fungo não identificado (NI) & 6,25 \\
Sementes sem contaminação & 24,00 \\
Sementes germinadas & 8,25 \\
\hline
\end{tabular}

* Quantidade encontrada em um total de 400 sementes.

NI - fungo não identificado.

No estudo com mudas, foram constatadas a crosta-marrom, o oídio, a fumagina, relatadas em "mudas passadas" de T. serratifolia (ipê-amarelo do cerrado) por Ferreira (1989). O autor, por extensão, as considerou em $T$. chrysotricha.

A crosta-marrom é causada pelo fungo Apiosphaeria guaranitica (Speg.) Hoehnel. Como as mudas podem permanecer no viveiro, até o segundo ano de vida, os sintomas da doença foram observados em todas as fases de desenvolvimento, inclusive naquelas com menos de 1 ano. A doença provoca redução da área fotossintetizante e pode induzir à queda de folhas. Verificou-se uma incidência de $90 \%$ de mudas doentes, em variados graus de severidade. Pequenas manchas, circulares, de coloração amarelo-clara, coalescentes, foram detectadas em plantas jovens, ocasionando perfurações nas folhas. Como as manchas foram observadas em folhas jovens que já apresentavam a crosta-marrom, acredita-se que sejam lesões iniciais causadas pelo fungo $A$. guaranitica, conforme relatado por Lima et al. (1976).

O oídio foi constatado em mudas com idade variando entre 3 a 6 meses, mantidas sob condições de sombreamento e baixa umidade, em estufa de plástico e sombrite. $\mathrm{O}$ fungo colonizou limbos foliares formando áreas esbranquiçadas, de aspecto pulverulento, em ambas as faces. Exame do micélio revelou conidióforos e conídios típicos do gênero Oidium. Esta doença foi relatada por Ferreira (1989) somente em mudas de T. serratifolia.

Uma mancha foliar desconhecida foi verificada em mudas, com frutificações do fungo Phyllosticta sp. As lesões necróticas eram de coloração marrom ou parda, com formato e tamanho variados, circundados por 
um halo avermelhado. Sobre as lesões observou-se pequenos pontos escuros, constituídos pelos picnídios do fungo. Os picnídios são globosos, pardos e subepidérmicos e os conídios são unicelulares, ovóides, e hialinos. Esta doença merece ser estudada, por não ter sido relatada ainda.

A fumagina encontrada sobre folhas de ipê-amarelo foi decorrente da ação de insetos sugadores. Tais insetos ao excretarem substâncias açucaradas sobre as folhas, criam condições para o desenvolvimento de fungos. Uma fumagina, freqüente em folíolos de mudas de T. chrysotricha e de Tabebuia sp. foi descrita por Ferreira (1989). O fungo de micélio escuro (provavelmente da família Capnodiaceae) distende-se sobre as superfície dos folíolos e pecíolos. Esse desenvolvimento fúngico acarreta danos ao desenvolvimento das folhas, devido à redução da taxa fotossintética. A incidência da fumagina e sua severidade não foram avaliadas neste estudo.

Uma última observação em mudas foi a presença de lesões foliares nas mudas decorrentes da falta de água no substrato, em mudas jovens, localizadas nas bordaduras dos canteiros. Tais folhas apresentavam sintoma de "V" invertido citado por Auer (1996), quando da ocorrência de umidade relativamente baixa no solo, associada a ventos frios permanentes.

No estudo em árvores urbanas, o levantamento revelou a presença da crostamarrom, da fumagina $\mathrm{e}$ da mancha desconhecida. A incidência das doenças foi visualmente maior em ruas mais movimentadas. A fumagina foi encontrada principalmente em ruas de tráfego intenso. Este efeito do trafego sobre a ocorrência das doenças poderia ser explicada pela maior movimentação do vento, como agente dispersor de propágulos dos patógenos (Kessler Jr., 1981), ou pelo estresse causado para as plantas tornando-as mais suscetíveis às doenças.

Alguns problemas de origem abiótica foram também verificados em árvores como, por exemplo, sintomas de "V" invertido nas folhas e fissuramento excessivo da casca. Encontraram-se, também, danos em árvores, expressos na forma de cancros e cicatrizes causados por injúrias diversas e podas mal conduzidas.
Os resultados apontaram a necessidade de se estabelecer estudos sobre a presença de doenças em espécies arbóreas destinadas ao uso em arborização urbana, pois em cada cidade podem ser encontrados problemas locais não registrados na literatura e de importância regionalizada.

\section{REFERÊNCIAS}

AUER, C.G. Doenças das árvores urbanas. Colombo: EMBRAPA-CNPF. 1996. 18p. (EMBRAPA-CNPF. Documentos, 28).

BARNETT, H.L.; HUNTER, B.B.. Illustrated genera of imperfect fungi. Burgerss Publishing, Minneapolis, 3 ed. 241 p. 1972.

CARVALHO, W.L.; MUCHOVEJ, J.J. Fungos associados a sementes de essências florestais. Revista Árvore, Viçosa, 15(2): 173178. 1991.

FERREIRA, F.A. Patologia Florestal; principais doenças florestais no Brasil. Sociedade de Investigações Florestais, Viçosa. 570p. 1989.

\section{INSTITUTO DE PESQUISA E PLANEJAMENTO URBANO DE CURITIBA - IPPUC. Histórico de dados do município de Curitiba. Curitiba.163p. 1991.}

KESSLER JR, K.J. Considerations of microclimate-leaf disease relations in arboriculture. Journal of Arboriculture, v.7, n.7, p.169-173. 1981.

LIMA, D.M.M.; REIS, M.S.; SHIMOYA, C. Etiologia e histopatologia da mancha foliar de Tabebuia serratifolia, ipê-amarelo, causada por Apiosphaeria guaranitica. Experientiae, Viçosa, 21(1): 1-20. 1976.

LUZ, W.C. da. Identificação dos principais fungos das sementes de trigo. Embrapa-CNPT, Passo Fundo, 28 p.(Circular Técnica, 1). 1987.

MAACK, R. Geografia do estado do Paraná. BADEP/UFPR/IBPT, Curitiba, 350p. 1968.

MARCHETTI, L.; NANNI, C.; VAI, N. Principali problemi fitosanitari del verde urbano e relativi indirizzi di difesa. Informatore Fitopatologico, 4, p.23-27, 1997. 
MILANO, M. S. Avaliação e análise da arborização de ruas de Curitiba-PR. Tese. Mestrado. Curso de Pós-Graduação em Engenharia Florestal. Curitiba. 130p. 1984.

NEERGAARD, P. Seed pathology. The MacMillan Press, London, v.1. 839p. 1977.

RAGAZZI, A. Le specie quercine e l'ambiente urbano: consigli per un coretto impiego e analisi delle problematiche sanitarie. Informatore Fitopatologico, 6, p.41-44, 1998.

SANTOS, A.F. dos; GRIGOLETTI JUNIOR, A.; AUER, C.G. Transmissão de fungos por sementes de espécies florestais Floresta, Curitiba, 30(1/2): 119-128. 2000.

SUTTON, B.C. The Coelomycetes. Commonwealth Mycological Institute, 650 p. 1981. 